\author{
FINAL REPORT \\ U.S. Department of Energy
}

\title{
RATIONAL SYNTHESIS OF IMPRINTED ORGANOFUNCTIONAL SOL-GEL MATERIALS FOR TOXIC METAL SEPARATION
}

\author{
Principal Investigators: Ziling (Ben) Xue \\ Department of Chemistry \\ University of Tennessee \\ Knoxville, TN 37996-1600 \\ Phone: 865-974-3443; Fax: 865-974-3454; Email: xue@utk.edu \\ Craig E. Barnes \\ Department of Chemistry \\ University of Tennessee \\ Knoxville, TN 37996-1600 \\ Phone: 865-974-3446; Fax: 865-974-3454; Email: cebarnes@utk.edu \\ Shang Dai $^{3}$ \\ Chemical Technology Division \\ Oak Ridge National Laboratory \\ Oak Ridge, TN 37831-6181 \\ Phone: 865-576-7307; Fax: 865-574-6442; Email: dais@ornl.gov
}

Project Number: EMSP No. 60096

Grant Number: DE-FG07-97ER14817

Project Duration: September 15, 1997 to September 14, 2001 


\section{Table of Contents}

1. Cover Page $\quad$....................................................................................

2. Table of Contents $\quad$........................................................................ 2

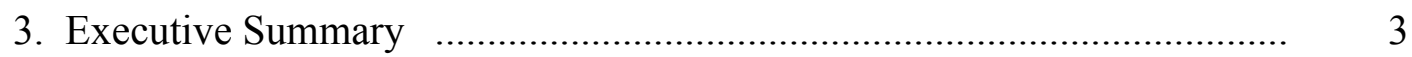

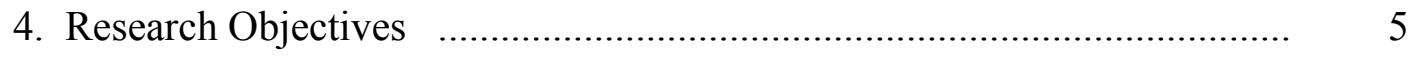

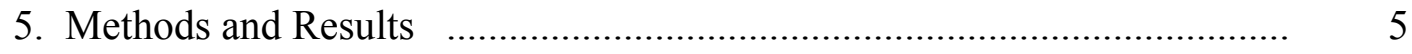

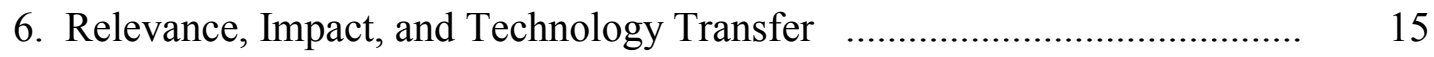

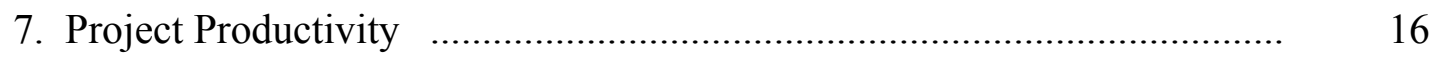

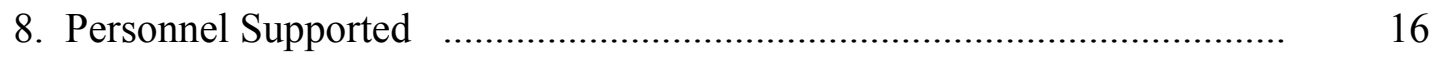

9. Peer Reviewed Publications ................................................................ 17

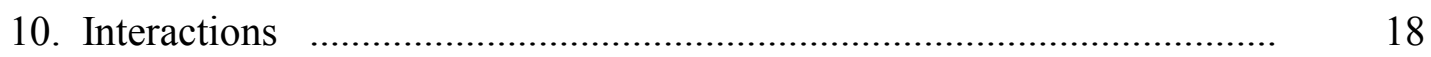

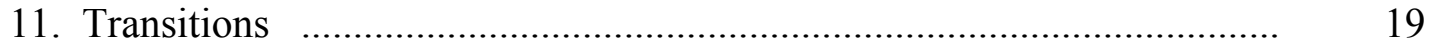

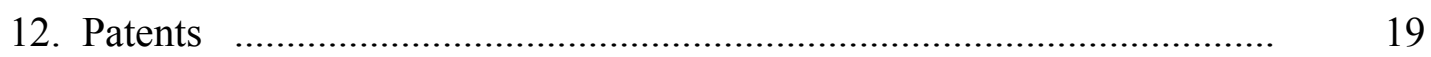

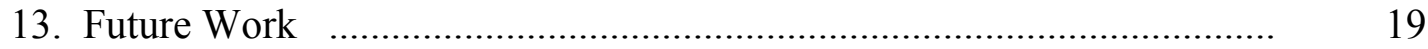

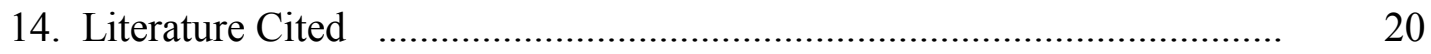




\section{Executive Summary}

This Environmental Management Science Program (EMSP) project united the efforts of three research groups at the University of Tennessee and Oak Ridge National Laboratory to develop principles, methodologies, and new materials designed to solve the separation problems in environmental and waste management. Included within this project were rational design and synthesis of imprinted sol-gel materials containing functional groups through template approaches as well as the development of a scientific basis for metal ion binding and recognition by such tailored hybrid inorganic-organic materials. Silica and alkaline-stable mixed metal oxides were either grafted or imbedded with ligands with high selectivity for target toxic metals, and the "imprinting" principle was used to "recognize" and bind the target metal ions. Our approaches utilized both the metal-ligand complexation and the tailored impressions of the template metal ions in the imprinted cavities. Such imprinted organofunctional sol-gel networks demonstrated both high selectivity and capacity. These novel imprinted, hybrid sol-gels exhibit selectivities for binding targeted ions from aqueous solution which, to our knowledge, are the highest reported in the literature. In addition, these hydrophilic oxides show fast metal ion binding kinetics, and can be quickly and easily recycled. Significant progress in the following task areas was made as a result of the DOE-EMSP support:

1. The general feasibility of using hydrophilic, porous metal oxide based materials as sorbents for metal ions extraction from aqueous solutions has been clearly demonstrated. Functional groups with high affinities for target metals can either be grafted to or embedded in the porous oxides to give new hybrid sol-gel sorbents for toxic metal separation. 
2. New hybrid sol-gel materials have been prepared by simple, one step procedures which exhibit fast binding kinetics, and high capacities and selectivities for $\mathrm{Cu}^{2+}, \mathrm{UO}_{2}^{2+}, \mathrm{Sr}^{2+}$, and $\mathrm{Cs}^{+}$ions. Some of the functional groups to be grafted are off-the-shelf chemicals that are readily incorporated into sol-gels. In addition, alkaline-stable, mixed zirconia-silica sol-gels were developed, and found to be excellent candidates for separations of toxic metals from highly alkaline wastes, a major challenge in environmental and waste management.

3. Several different methods for preparing imprinted, hybrid sol-gel sorbents have been developed. Our imprinting studies have resulted in several generations of procedures which have exhibited increased control of the molecular architectures critical to the design and synthesis of ion selective sorbents. The two properties that are important to obtain fast and selective ion binding are mesoporosity and multiple binding imprints made up by a combination of surface groups (e.g., $\mathrm{Si}-\mathrm{OH}, \mathrm{Si}-\mathrm{O}-\mathrm{Si}$ ) and tethered ligands. Furthermore, based on the hierarchical ( $3^{\text {rd }}$-generation $)$ imprinting studies, better, more selective ion binding may be attained when the template-ligand complex is present during the condensation of colloidal silica particles as the silicate pore surfaces are formed. Binding studies with copper(II) give the highest distribution coefficients $\left(K_{\mathrm{d}}\right)$ and selectivities reported in the literature to date for metal ion extraction by sol-gel derived sorbents. Although the studies we completed were mainly designed to illustrate the concepts underlying ion imprinting strategies, we see no obvious impediments to the application of these procedures to a wide variety of ligands, metal oxide support materials, and metal ions targeted by DOE-EM programs. 


\section{Research Objectives}

The overall goal of this project was to understand chemistry of toxic metal ion complexation with organofunctional groups that are grafted on sol-gels, and to develop and apply imprinting principles to the synthesis of hybrid inorganic-organic sol-gel materials which would selectively bind target ions. The specific objectives were: (a) to synthesize and characterize imprinted hybrid inorganic-organic materials using templates bonded to ligands for toxic metal binding and removal; (b) to evaluate the capacity and selectivity of such materials for binding target ions; (c) to study and develop methods for the removal of the target toxic metal ions and the regeneration of the imprinted sol-gel materials; (d) to apply this knowledge to the development of cost efficient sol-gel ion sorbents and novel technologies for the removal of toxic metal ions from fluid wastes. In addition to the objectives listed above, we expected that the results of these studies could form a basis for the fundamental design principles for imprinted organofunctional sol-gel materials, and contribute to the understanding of metal ion recognition and separation in DOE environmental management and waste and treatment. ${ }^{1}$

\section{Methods and Results}

Three research groups that were involved in this project brought together complementary expertise and capabilities with respect to this project. A variety of experimental techniques were used, which include inorganic, organic and solid-state synthesis, solution and solid-state NMR, fluorescence spectroscopy, X-ray scattering (SAXS), and scanning and transition electron microscopy (TEM).

We have investigated and developed the chemistry of imprinted organofunctional sol-gels targeted for the separation and recovery of toxic metals. The results from the EMSP supported research show that (a) the ligand $\mathrm{L}$ in the organofunctional sol-gels retain their high affinity for the target metal ions; (b) the imprinting, which takes place during the formation of these rigid solid state networks, further enhances both their capacities and selectivities; (c) the removal of metal ions from the aqueous solutions by these hydrophilic metal oxide-based sol-gels is fast. Metal ion binding and release in these sorbents can easily be controlled by a number of factors including $\mathrm{pH}$ and nature of the solvent. Thus, these sorbents should also be very cost efficient due to their quick and simple recyclability. Finally, the hydrophilic nature of the hydroxylated surfaces of metal oxide-based solids made ion transport in these porous solids intrinsically fast. This property potentially solves a problem frequently encountered with ion exchange polymers based on hydrophobic organic resins. ${ }^{2}$ Ten peer-reviewed papers were published, and 20 presentations were presented at national and regional meetings and EMSP workshops, and several additional papers are in preparation. 


\section{Background}

The sol-gel process refers to a multitude of reactions which employ a wide variety of alkoxide precursors to prepare many different products and has been applied most often to the production of glasses and ceramic oxides. ${ }^{3}$ The particles that develop in the colloidal sol crosslink form a gel which is subsequently dried to form a porous glass under very mild conditions.

A new class of "hybrid inorganic-organic" materials has emerged in the last 10 years with an equally wide range of applications. ${ }^{4}$ Hybrid sol-gels are prepared by entrapping or covalently bonding organic groups into the developing metal oxide solid network as it is formed. The most common method used to bind organic groups to the developing metal oxide matrix is by adding a "bifunctional" reagent containing a trialkoxysilane group attached to the organic group $\left[(\mathrm{RO})_{3} \mathrm{Si} \sim \mathrm{L}\right]$. Through a sequence of solvolysis and condensation reactions, the $-\mathrm{Si}(\mathrm{OR})_{3}$ group becomes grafted into surfaces of the metal oxide matrix.

Ion exchange resins have been developed as one approach to remediation and pollution prevention with regard to fluid wastes. ${ }^{2}$ Ligands are covalently bonded to an insoluble organic polymer to avoid the loss of extractant to the aqueous phase. Target ions are removed from the aqueous phase either through ion exchange or complexation with the ligands. The polymer loaded with the metal is then treated with an appropriate solution to strip the metal and regenerate the resin. The ion exchange technique by organic resins is popular due to operational simplicity and environmental compatibility, and high capacity and selectivity which may be attained. However, slow kinetics of ion extraction from aqueous phase by the hydrophobic organic polymers, high initial cost of a polymeric reagent (which is offset by recyclability) and regenerants that are sometimes required, are among the disadvantages in the use of organic ion exchange resins. ${ }^{2}$

Silica gels, and more recently sol-gel derived materials, have been used in preparing inorganic sorbents containing covalently attached ligands. ${ }^{5}$ In this approach, the surface hydroxyl groups $-\mathrm{OH}$ react with $(\mathrm{RO})_{3} \mathrm{Si} \sim \sim \mathrm{L}$, thus grafting the ligands on silica gel surface. These gels do not, however, exhibit high selectivities between different metal ions with similar affinities for the tethered ligands. As will be described later, our functionalized, imprint-coated sol-gels address this issue.

An imprinted material is one in which tailored impressions or "cavities" are present in its outer and, if porous, inner surfaces (Figure 1). ${ }^{6}$ A "cavity" in an imprinted material refers to the predetermined arrangement of different interactions that develops or is "templated" into the structure of a material as it is being formed. The polymer "grows" around the

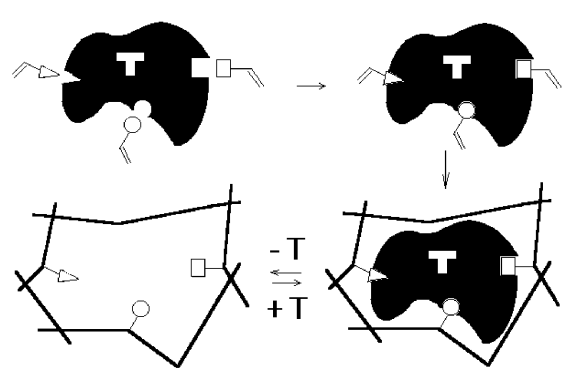

Figure 1. Imprinting by a template $\mathrm{T}$ and functional groups in a cross-linked polymer. ${ }^{6}$ 
template conforming to both its steric and electronic (polar and nonpolar contacts) properties to ultimately produce the "cavity". Several groups have reported imprinted materials based on cross-linked organic polymers. ${ }^{6,7}$

\section{Mesoporous $\mathrm{TiO}_{2}-\mathrm{SiO}_{2}$ Sorbents for $\mathrm{Cs}^{+}$and $\mathrm{UO}_{2}{ }^{2+}$}

Prior to the start of our current EMSP work, we had reported our preliminary results of imprinting pure silicate sol-gels. ${ }^{8}$ We briefly investigated the properties of unfunctionalized metal oxide supports to determine what factors influence the uptake and binding of both $\mathrm{UO}_{2}{ }^{2+}$ and $\mathrm{Cs}^{+}$to $\mathrm{M}^{\prime}-\mathrm{OH}$ groups inherent to the metal surfaces of metal oxides.

$\boldsymbol{U O}_{2}{ }^{2+}$. Microporous metal oxides such as silica, titania, zirconia and mixed oxides $\mathrm{M}^{\prime} \mathrm{O}_{2}-\mathrm{SiO}_{2}$ $\left(\mathrm{M}^{\prime}=\mathrm{Ti}, \mathrm{Zr}\right)$ readily adsorb uranyl ions via ion exchange reactions with surface silanols. ${ }^{9}$ Little is known, however, about the adsorption properties of mesoporous analogues of these oxides. We have prepared a series of surfactant ordered, mesoporous mixed $\mathrm{TiO}_{2}-\mathrm{SiO}_{2}$ oxide $(100 \% \rightarrow$ $0 \% \mathrm{Si}$ vs. Ti) materials and studied the binding affinities they exhibit toward buffered solutions $\left(\mathrm{CH}_{3} \mathrm{COOH} / \mathrm{CH}_{3} \mathrm{COONa} ; \mathrm{pH} \sim 5\right)$ of the $\mathrm{UO}_{2}{ }^{2+}$ ions. Kinetic studies conclusively showed that uranyl uptake by mesoporous sorbents is over 200 times faster than observed for comparable microporous materials (Figure 2).

The total surface areas observed in the series decreased with increasing titanium content. Maxima in the pore diameter distributions (BET) ranged from 25-75. . Despite the observed lowest overall surface area $\left(210 \mathrm{~m}^{2} / \mathrm{g}\right)$, pure, mesoporous titania $\left(d_{\text {ave }}=52 \AA\right)$ exhibited the highest binding capacity for $\mathrm{UO}_{2}{ }^{2+}(66 \mu \mathrm{mole} / \mathrm{g})$ in the series. This result is consistent with uranyl binding primarily to $\mathrm{TiO}_{2}$ sites on the surface in all mixed oxides prepared in this study (Dai el al., 1999).

$\mathrm{Cs}^{+}$. Several groups have reported the use of metal, block copolymers in templating ordered mesopore structures in sol-gels. ${ }^{10}$ We have investigated the use of block copolymers in developing mesoporosity in base-stable, mixed $\mathrm{TiO}_{2}-\mathrm{SiO}_{2}$ oxide materials for $\mathrm{Cs}^{+}$extraction from aqueous solutions. Mixing $\mathrm{Si}(\mathrm{OMe})_{4}(\mathrm{TMOS})$ and $\mathrm{Ti}(\mathrm{O}-i-\mathrm{Pr})_{4}$ with the neutral block copolymer Tergitol 15-s-15 gave mesoporous $\left(d_{\text {ave }}=44 \AA\right.$ ) $\mathrm{TiO}_{2}$ $\mathrm{SiO}_{2}$ powders. In the $\mathrm{pH}$ region of 7-10, these sorbents removed $>90 \%$ of $\mathrm{Cs}^{+}$from solution within $1 \mathrm{~h}\left(\mathrm{Cs}^{+}\right.$capacity: 0.5 $\mathrm{mmol} / \mathrm{g}$ ). Competition studies with both $\mathrm{K}^{+}$

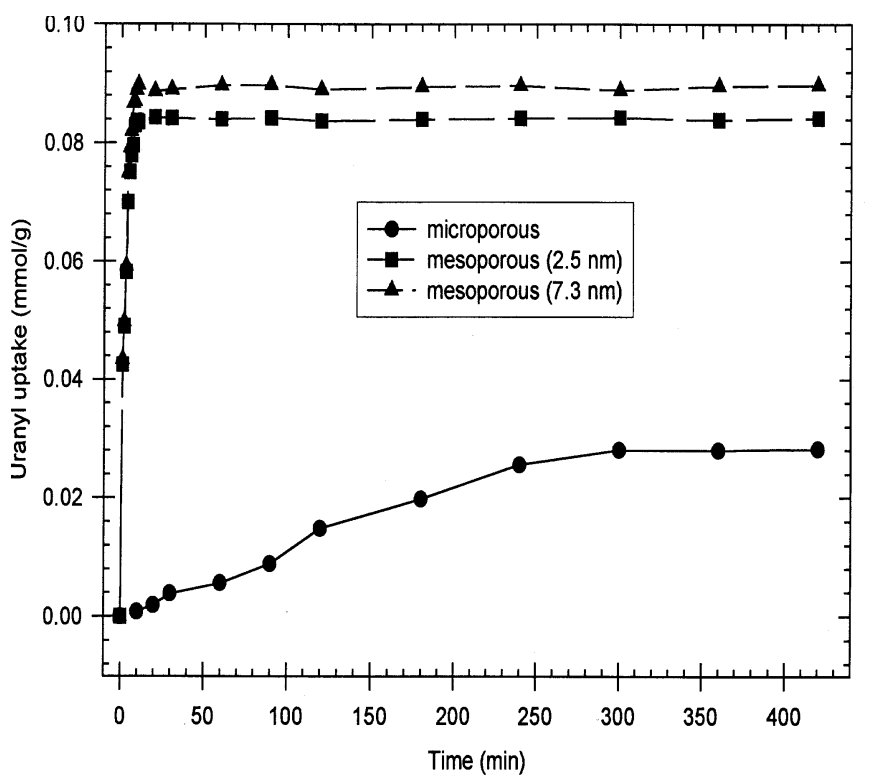

Figure 2. $\mathrm{UO}_{2}{ }^{2+}$ uptake vs. time by mesoporous and microporous sol-gel sorbents 
and $\mathrm{Na}^{+}$revealed that these sorbents removed $\mathrm{Cs}^{+}$selectively from solutions containing a 10-fold excess of $\mathrm{K}^{+}$and a 30 -fold excess of $\mathrm{Na}^{+}$(Barnes et al., manuscript in preparation).

\section{Hybrid Sol-Gel Sorbents - Sol-Gels Containing Tethered or Doped Organic Ligands}

Ligands grafted on solid support have been extensively studied as sorbents for toxic metal separation.,11,12 Many of these materials, while highly selective for the target metals with good capacity, often require multi-step synthesis or a second functional group in hydrophobic polymers to enhance their hydrophilicity and kinetics of metal ion-uptake. ${ }^{13}$ When we started the current DOE-funded research in 1997, there had been few studies of ligand-containing, hydrophilic sol-gels as new sorbents for toxic metal separations in multi-cycles. We thus studied one-step sol-gel processes from off-the-shelf chemicals to generate ligand-tethered or -doped $\mathrm{SiO}_{2}$ materials, and investigated their potentials as a new type of sorbents in multi-cycles of toxic metal separation.

Ligand-tethered sol-gels. We initially targeted $\mathrm{Cu}^{2+}$ in the current study and investigated several ligand-tethered sol-gels for repeated $\mathrm{Cu}^{2+}$ separation. Copper(II) is among the 13 toxic metal species on the EPA's priority pollutant list, and is $\mathrm{RCRA}^{14}$ regulated. ${ }^{15}$ Sol-gels tethered with ethylenediamine (aapts, Figure 3) were found to be selective for $\mathrm{Cu}^{2+}$ removal in the presence of competitive $\mathrm{Cd}^{2+}$ and $\mathrm{Zn}^{2+}$. The $\mathrm{Cu}^{2+}$-uptake capacities of these sol-gels are comparable to some known, published $\mathrm{Cu}^{2+}$ sorbents. These ligand-tethered materials, which were easily prepared from off-the-shelf chemicals in ca. $1 \mathrm{~h}$, were hydrophilic and thus showed fast kinetics of metal upload and removal (from the gels) in aqueous solutions. The ligand-tethered sol gels loaded with $\mathrm{Cu}^{2+}$ ions were regenerated with acid, and the materials could then be used in subsequent $\mathrm{Cu}^{2+}$ removal cycles. The work here shows that these hydrophilic ligand-tethered sol-gels are a good alternative to ligand-tethered organic polymers for toxic metal separation (Xue et al., 2000).

Phosphonic acid groups are known to have high affinities for hard, oxophilic cations such as uranyl $\left(\mathrm{UO}_{2}{ }^{2+}\right)$ and $\mathrm{Sr}^{2+}$. We developed syntheses for a family of bifunctional mono-, bis- and linked phosphonate esters containing pendant alkoxysilyl groups for tethering to sol-gel surfaces (Figure 3). The surface-bound ester ligands were not found to be effective for removing either $\mathrm{Sr}^{2+}$ or uranyl from aqueous solution. After treatment with $\mathrm{Me}_{3} \mathrm{SiBr}$ followed by water at room temperature (a procedure for the hydrolysis of phosphonate esters under mild conditions), the free acids were obtained in the gel. Simultaneously, unreacted silanol $\equiv \mathrm{Si}-\mathrm{OH}$ sites on the gel surface are silylated in this procedure to give $\equiv \mathrm{Si}-\mathrm{O}-\mathrm{SiMe}_{3}$ and removed from competitive binding of the targeted cations. These "reverse phase" ion sorbents were found to have higher affinities for the target cations than nonsilylated sorbents. In the case of uranyl binding studies, increases in the $K_{\mathrm{d}}$ values of up to 4 were observed for imprinted bisphosphonic acid containing gels while affinities for a $\mathrm{Ca}^{2+}$ competitor $\left(\left[\mathrm{Ca}^{2+}\right]>10\left[\mathrm{UO}_{2}{ }^{2+}\right]\right)$ remained low $\left[K_{\mathrm{d}}\left(\mathrm{UO}_{2}{ }^{2+}\right) \sim 500\right.$ $\left.K_{\mathrm{d}}\left(\mathrm{Ca}^{2+}\right)\right]$ (Barnes et al., manuscript in preparation). 
<smiles>CO[SiH2]CCCNCCN</smiles>

" $\mathrm{H}_{2} \mathrm{~N} \sim \mathrm{NH} \sim \mathrm{Si}(\mathrm{OMe})_{3}$ "

appts grafting ligand

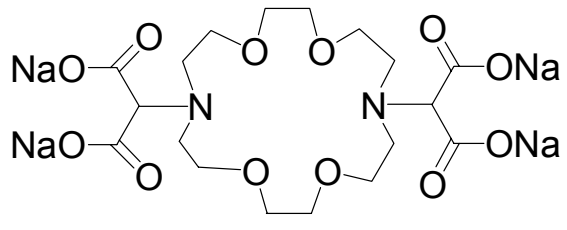

$\mathrm{Na}_{4}$ oddm doping ligand<smiles>CCO[SiH2]CCP(=O)(OCC)OCC</smiles>

monophosphonate grafting ligand

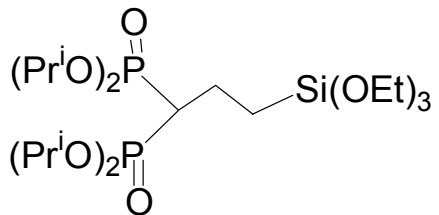

bisphosphonate grafting ligand<smiles>CO[SiH2]CC[Pb](=O)OCCOP(=O)(CC[SiH2]OC)OC</smiles>

linked phosphonate grafting ligand

Figure 3. Some ligands used in the preparation of tethered and doped sol-gels.
We also developed base-stable $\mathrm{ZrO}_{2}-\mathrm{SiO}_{2}$ mixed oxide sorbents containing an anchored $-\mathrm{P}(=\mathrm{O}) \mathrm{O}_{2}{ }^{2-}$ yielded from the monophosphonate ligand in Figure 3. This sol-gel sorbent was stable in 1.0 $\mathrm{M} \mathrm{NaOH}$, and effective at removing $\mathrm{Sr}^{2+}$ ions from neutral and alkaline solutions. At $\mathrm{pH}$ 6.4, $97 \pm$ $3 \%$ of the $\mathrm{Sr}^{2+}$ was extracted from a $24.0 \mathrm{ppm}$ solution in $24 \mathrm{~h}$. When placed in an alkaline solution (pH 14.0), the sorbents absorbed $92 \pm 5 \%$ of the $\mathrm{Sr}^{2+}$ ions from a $35.8 \mathrm{ppm}$ solution in $24 \mathrm{~h}$. In the presence of competing $\mathrm{Ca}^{2+}$ ions, the mixed oxide sorbent removed $89 \pm 7 \%$ of the $\mathrm{Sr}^{2+}$ ions and $97.6 \pm$ $0.4 \%$ of the $\mathrm{Ca}^{2+}$ ions from a solution containing 37.3 ppm $\mathrm{Sr}^{2+}$ and $139.5 \mathrm{ppm} \mathrm{Ca}^{2+}$.

This mixed oxide sol-gel sorbent containing anchored monophosphonate ligand offers reasonable $\mathrm{Sr}^{2+}$ kinetics. Up to $90 \%$ of the $\mathrm{Sr}^{2+}$ in solution was absorbed into the sorbent in the first hour of the extraction. After a $\mathrm{Sr}^{2+}$ extraction cycle, the metal ions were easily stripped from the sol-gel with EDTA to regenerate the sorbent (Xue et al., manuscript in preparation).

Ligand-entrapped sol-gels. A second approach to introducing ligand binding groups into sol-gels involves simply entrapping them in pores where they remain due to their size relative to pore chamber openings or because they adhere to the pore surface strongly. The synthesis of entrapped ligand sol-gel sorbents is simplified because no covalent attachment to the surface is needed. Crown-ether ligands have been used to remove toxic metal ions from aqueous solution via liquid-liquid extraction techniques ${ }^{17}$ as well as by tethering them to both organic and inorganic supports. ${ }^{18}$ We developed a simple, one step procedure by which the 7,16-diaza-18-crown-6 ligand, further functionalized with malonate groups attached to nitrogen $\left(\mathrm{Na}_{4} \mathrm{oddm}\right.$, Figure 3$)$ may be doped in the pores of mesoporous solgels. These doped sorbents selectively bind $>99 \% \mathrm{Sr}^{2+}$ from aqueous solution in the presence of a 4-fold excess of $\mathrm{Ca}^{2+}$ competitor ions.

Sol-gels doped with the tetrasodium salt of $\mathrm{Na}_{4}$ oddm ligand was prepared in $c a$. $1 \mathrm{~h}$ by simply mixing $\mathrm{Na}_{4}$ oddm with $\mathrm{Si}(\mathrm{OMe})_{4}$ and hydrolyzing the mixture. Conditioning the doped gels removes all weakly bound crown ligand such that no further leaching was observed in 
subsequent binding studies. The results of binding studies (Table 1), illustrate the high affinity and capacity for $\mathrm{Sr}^{2+}$ exhibited by these sorbents, and the effect of an added $\mathrm{Ca}^{2+}$ competitor ion. These crown doped sol-gels do not suffer any degradation in $\mathrm{Sr}^{2+}$ uptake and capacity after at least 3 cycles of $\mathrm{Sr}^{2+}$ removal by acid wash and neutralization (Xue et al., 2000).

Table 1. $\mathrm{Sr}^{2+}$ Extraction by Embedded $\mathrm{Na}_{4} \mathrm{Oddm}$ Ligand

\begin{tabular}{|c|c|c|c|c|c|}
\hline & Initial $\left[\mathrm{Sr}^{2+}\right]^{\mathrm{a}}$ & Final $\left[\mathrm{Sr}^{2+}\right]^{\mathrm{a}}$ & Capacity $^{b}$ & $\boldsymbol{K}_{\mathrm{d}}^{\mathrm{c}}$ & $\mathrm{Sr}^{2+}$ Removed (\%) \\
\hline Control $^{\mathrm{d}}$ & $27.600 \pm 0.006$ & $24.3 \pm 0.7$ & $6.3 \times 10^{-3}$ & 22 & 12 \\
\hline Doped gel & $27.600 \pm 0.006$ & $0.33 \pm 0.01$ & $4.9 \times 10^{-2}$ & 11,000 & 99 \\
\hline Doped gel $^{\mathrm{e}}$ & $27.900 \pm 0.006^{\mathrm{e}}$ & $0.010 \pm 0.003$ & $5.3 \times 10^{-2}$ & $3.6 \times 10^{5}$ & $>99$ \\
\hline
\end{tabular}

${ }^{\mathrm{a}} \mathrm{ppm}$

${ }^{\mathrm{b}}$ Capacity in mmol of $\mathrm{Sr}^{2+} / \mathrm{g}$ of gel

${ }^{\mathrm{c}} K_{\mathrm{d}}$ in [mg of $\mathrm{Sr}^{2+} / \mathrm{g}$ of gel] / [ppm of $\mathrm{Sr}^{2+}$ remaining]

${ }^{\mathrm{d}}$ Control containing no $\mathrm{Na}_{4}$ oddm ligand

${ }^{\text {e }}$ Competitive binding in a solution containing $118 \mathrm{ppm} \mathrm{Ca}^{2+}$

These results illustrate that simply entrapping ligands in the pores of sol-gel solids can lead to robust sorbents which are effective in selectively removing targeted metal ions from aqueous solution. Thus the variety of ligands for which this method is applicable should be broad.

\section{Imprinting Studies of Organofunctional Hybrid Sol-Gel Sorbents}

$\mathbf{1}^{\text {st }}$-Generation imprinting. Imprinting sol-gel materials requires the ability to control the

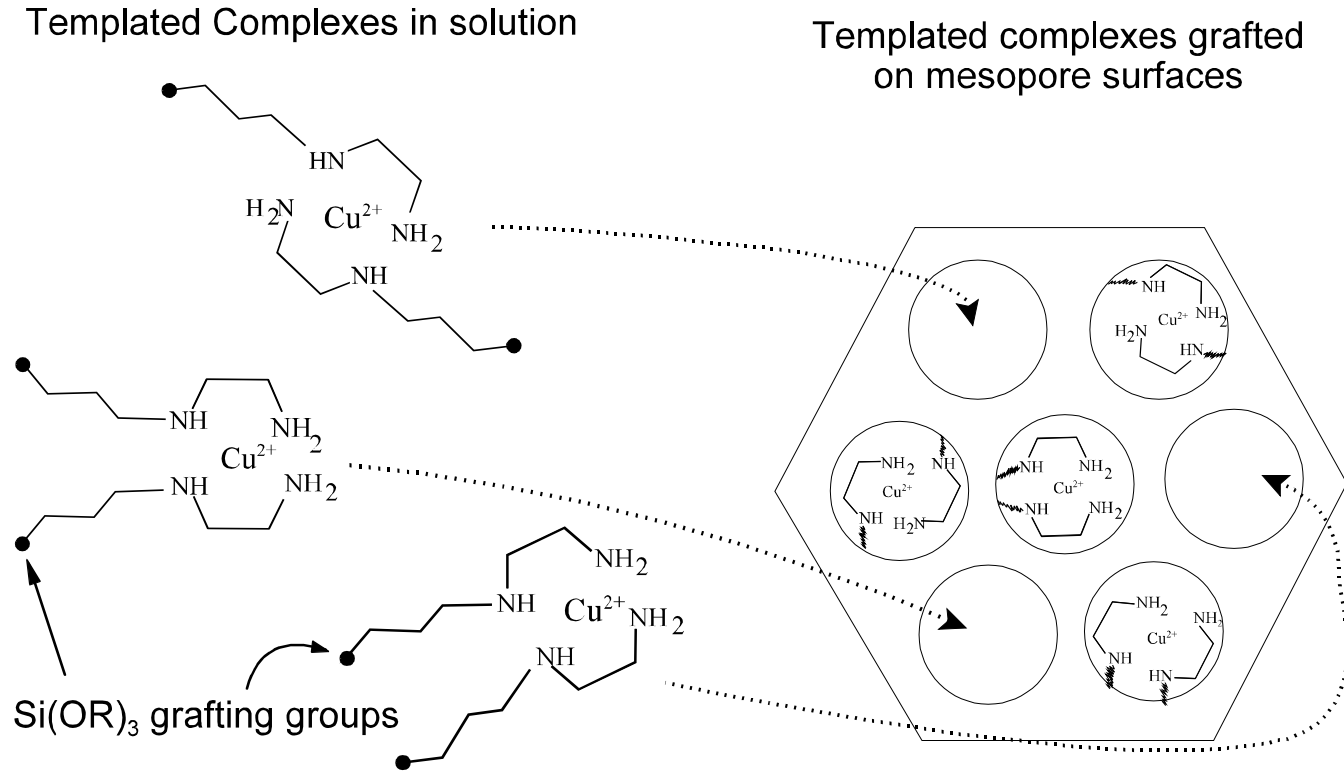

Figure 4. 1st-Generation imprint coating of mesoporous sol-gel supports structure of the developing solid matrix at several different length scales. At the nanometer scale, the pore size and order must be controlled so that ion transfer kinetics are fast without sacrificing overall surface 
area. Our EMSP studies reported above with meso- and microporous silicas have shown that mesoporosity is required for acceptable ion transport kinetics. At the atomic level (1-3 $\mathrm{A})$, control of the imprinted structure focuses not only on the arrangement of any ligands that might be grafted to the surface but also on the arrangement of surface silanols $(\mathrm{Si}-\mathrm{OH})$. Controlling both should increase the affinity, selectivity, and capacity of the system for a specific target ion.

Surfactant based porosity templating in sol-gels was first described almost 10 years ago ${ }^{19}$ and has become an important technique in tailoring porosity in sol-gel chemistry. Exclusion of the developing silicate matrix from the hydrophobic interior of cylindrical surfactant micelles results in the formation of ordered, mesoporous sol-gels after removal of the surfactant by extraction or calcining. We observed, however, that the stability of the micelles in these mixtures can be disrupted when even low levels of $(\mathrm{RO})_{3} \mathrm{Si} \sim \mathrm{L}$ ligands are added to make hybrid, organic-inorganic sol-gel sorbents. These conflicting design requirements led to what we refer to as $1^{\text {st }}$-generation imprinting procedures wherein metal templated ligand assemblies $\left(\left[\mathrm{M}\left(\mathrm{L} \sim \sim \mathrm{Si}(\mathrm{OR})_{3}\right)_{n}\right]^{\mathrm{x}+}\right)$ are grafted onto the surfaces of preformed mesoporous sol-gel solids. Removal of the metal template leaves the set of $n$ ligands tethered to pore surfaces but in an organized manner based on the size and electronic signature (e.g., coordination geometry) of the template (Figure 4). Studies of $1^{\text {st }}$-generation $\mathrm{Cu}^{2+}$ imprint coated sorbents, prepared by reacting preformed mesoporous silicate sol-gels with the ethylenediamine $\mathrm{Cu}^{2+}$ complex, $\left[\mathrm{Cu}(\text { appts })_{2}\right]^{2+}$ gave evidence of true imprint binding. Table 2 summarizes $\mathrm{Cu}^{2+}$ binding studies with and without the presence of a $\mathrm{Zn}^{2+}$ competitor ion (chosen for its similar size and charge to $\mathrm{Cu}^{2+}$ ). Imprinting effects are clearly evident in the values of the relative selective coefficients $k^{\prime}\left(k^{\prime}=\right.$ $k_{\text {imprint-coated }} / k_{\text {control }} ; k=K_{\mathrm{d} \text { (target) }} / K_{\mathrm{d} \text { (competitor) }) .} k^{\prime}$ values as large as 40 were observed for imprinted sorbents which, to our knowledge, were the largest values reported for imprinted metal ion sorbents at that time this work was published (Dai et al., 1999).

Table 2. Competitive Loading of $\mathrm{M}_{1}\left(\mathrm{Cu}^{2+}\right)$ and $\mathrm{M}_{2}\left(\mathrm{Zn}^{2+}\right)$ by $\mathrm{Cu}^{2+}$-Imprinted and Control Blank Mesoporous Sorbents at pH 5.0 (Acetic Acid/Acetate Buffer).

\begin{tabular}{|c|c|c|c|c|c|c|c|}
\hline Type & Solution (M) & $\% \mathrm{Cu}^{2+} \mathrm{Abs}$ & $\% \mathrm{Zn}^{2+} \mathrm{Abs}$ & $\mathrm{Cu}^{2+} \boldsymbol{K}_{\mathrm{d}}^{\mathrm{a}}$ & $\mathbf{Z n}^{2+} K_{d}^{a}$ & $\boldsymbol{k}$ & $k^{\prime}$ \\
\hline nonimp-aapts & $0.001 \mathrm{Cu}^{2+} / 0.001 \mathrm{Zn}^{2+}$ & 98.5 & 96.6 & 6543 & 2872 & 2.3 & - \\
\hline imp-aapts & $0.001 \mathrm{Cu}^{2+} / 0.001 \mathrm{Zn}^{2+}$ & 99.8 & 82.9 & 44045 & 483 & 91 & 40 \\
\hline nonimp-aapts & $0.001 \mathrm{Cu}^{2+} / 0.005 \mathrm{Zn}^{2+}$ & 98.5 & 70 & 6539 & 233 & 28 & - \\
\hline imp-aapts & $0.001 \mathrm{Cu}^{2+} / 0.005 \mathrm{Zn}^{2+}$ & 99.6 & 52.6 & 23874 & 111 & 215 & 7.7 \\
\hline
\end{tabular}

${ }^{\text {a }} K_{\mathrm{d}}$ units: $\mathrm{mL} / \mathrm{g}$

$2^{\text {nd }}$-Generation imprinting. Although $1^{\text {st }}$-generation imprinted sorbents are quite promising, drawbacks to such coating procedures include complicated, two-step procedures involving different solvents, separate extraction or calcining steps as well as low ligand loadings. A $2^{\text {nd }}-$ generation imprinting procedure has been developed by our groups which addresses some of 
these problems. Ion-exchange reactions have been used extensively to prepare intercalation materials ${ }^{20}$ as well as to remove surfactants from "as-synthesized" mesoporous sol-gel materials. ${ }^{21}$ Surface anionic groups $\left(\mathrm{Si}^{-} \mathrm{O}^{-}\right)$ interact with the charged head groups of cationic surfactants $\left(\mathrm{M}_{1}^{+}\right)$in developing mesoporosity within the gelling, assynthesized solid. Instead of calcination to remove surfactant, a second cationic species such as a ligated template complex $\mathrm{M}\left[\mathrm{L} \sim \mathrm{Si}(\mathrm{OR})_{3}\right]_{\mathrm{n}}{ }^{m+}$, is intercalated into the pores, exchanging with and removing the surfactant. Subsequent reactions between the template complex and surface Si-OH groups
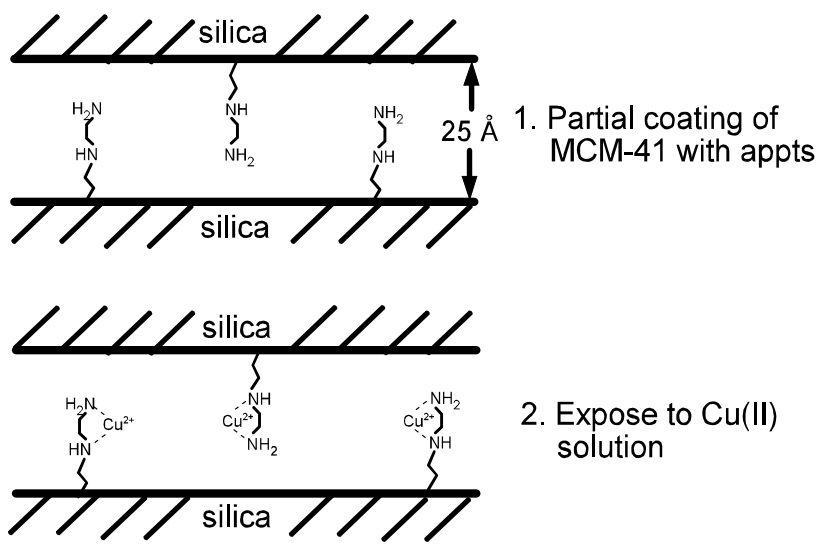
graft the templated ligand assemblies to the

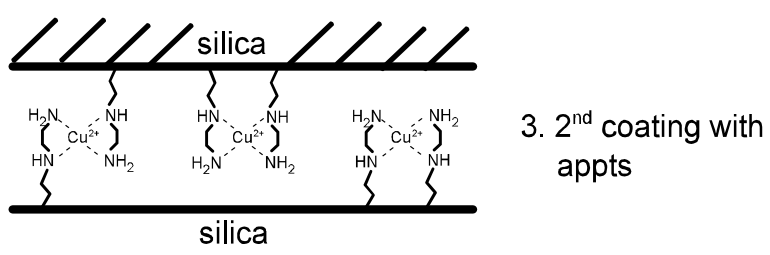

Figure 5. Stepwise imprint coating procedure pore surfaces.

We demonstrated the idea of ion-exchange coating with mesoporous MCM-41 and the $\left.[\mathrm{Cu} \text { (appts })_{2}\right]^{2+}$ and $\left.\left[\mathrm{UO}_{2} \text { (appts) }\right)_{2}\right]^{2+}$ grafting templates. As-synthesized MCM-41, still containing surfactant solution, was mixed with one of the templated species with mild heating $\left(50{ }^{\circ} \mathrm{C}\right)$. After subsequent washing and removal of the metal template with acid, ligand loadings were determined to be $\geq 1.0 \mathrm{mmol} / \mathrm{g}$ which surpasses the highest loadings $(\sim 0.7 \mathrm{mmol} / \mathrm{g})$ we had observed for the $1^{\text {st }}$-generation imprint coated sorbents described above. In all samples prepared via ion-exchange reactions, high surface areas were obtained after removal of the metal template. Based on these results, the $2^{\text {nd }}$-generation ion exchange procedure is an effective and simple method for the removal of surfactants from ordered sol-gels while simultaneously obtaining high loadings of grafted, templated ligand assemblies to the pore surfaces of sol-gel matrices (Dai et al., 1999).

We recently developed an important variation in imprint coating procedures (Dai et al., 2000). In this procedure a limited number of chelating ligands (in this case appts ligands) are covalently bound to the surface of MCM-41 (Figure 5). The partially coated material is then exposed to $\mathrm{Cu}^{2+}$ followed by a second round of coating with appts. Removal of the $\mathrm{Cu}^{2+}$ template with acid and reneutralization results in an ordered arrangement of appts ligands imprinted for $\mathrm{Cu}^{2+}$ recognition. Table 3 summarizes the $\mathrm{Cu}^{2+}$ binding results when $\mathrm{Zn}^{2+}$ is present. Both the $K_{\mathrm{d}}$ and $k^{\prime}$ (relative selectivity coefficient) values exhibited by step-wise imprinted sorbents are dramatically higher than nonimprinted control samples and are the largest that we have measured in our investigations thus far. 
Table 3. Stepwise Imprinted Sorbent Selectivity $\left(\mathrm{Cu}^{2+} \mathrm{Vs} \mathrm{Zn}^{2+}\right)$ Data

\begin{tabular}{|c|c|c|c|c|c|c|c|c|}
\hline Sorbent & $\begin{array}{l}C_{0} \mathrm{Cu}^{2+} \\
(\mathrm{ppm})\end{array}$ & $\begin{array}{c}C_{\mathrm{f}} \mathrm{Cu}^{2+} \\
(\mathrm{ppb})\end{array}$ & $\begin{array}{l}\mathrm{Cu}^{2+} K_{\mathrm{d}} \\
(\mathrm{mL} / \mathrm{g})\end{array}$ & $\begin{array}{l}C_{0} \mathrm{Zn}^{2+} \\
(\mathrm{ppm})\end{array}$ & $\begin{array}{c}C_{\mathrm{f}} \mathrm{Zn}^{2+} \\
(\mathrm{ppb})\end{array}$ & $\begin{array}{l}\mathrm{Zn}^{2+} K_{\mathrm{d}} \\
(\mathrm{mL} / \mathrm{g})\end{array}$ & $k$ & $k^{\prime}$ \\
\hline Non-imp. & 6.35 & 125 & 4,980 & 6.54 & 16 & 42,200 & 0.118 & \\
\hline $\mathrm{Cu}^{2+}$-imp. & 6.35 & 15 & 42,100 & 6.54 & 1770 & 269 & 156 & 1,330 \\
\hline Non-imp. & 15.89 & 210 & 7,470 & 16.35 & 101 & 16,000 & 0.466 & \\
\hline $\mathrm{Cu}^{2+}$-imp. & 15.89 & 32 & 49,100 & 16.35 & 7300 & 124 & 396 & 850 \\
\hline Non-imp. & 6.35 & 269 & 2,260 & 65.39 & 229 & 28,500 & 0.079 & \\
\hline $\mathrm{Cu}^{2+}$-imp. & 6.35 & 10 & 67,100 & 65.39 & 15,100 & 334 & 201 & 2,540 \\
\hline
\end{tabular}

Our results above showed, at least in one case, that step-wise imprinting could lead to extremely selective binding of a target in the presence of a competitor ion. It also addresses another, more pragmatic concern regarding the solubility of ionic template complexes used for grafting. Such complexes can have very limited solubility which would hinder or prevent their use in the grafting step in imprint coating procedures (e.g., uranyl-amine complexes have low solubility in water-alcohol solvent mixtures). This is potentially a serious problem in forming template ligand assemblies which must be delivered to internal pore surfaces for grafting. By first immobilizing half of the imprint ligands on the surface, complexation of the metal template should occur only where we require it to and thus is not subject to the same solubility limitations as when the entire template is initially formed in solution. The ability to tailor imprint procedures around such limitations as the solubility of the template is as important as the imprinting reaction itself and plays an important role in $\mathrm{UO}_{2}{ }^{2+}$ and $\mathrm{Sr}^{2+}$ imprinting methodologies.

$3^{\text {rd }}$-Generation imprinting - Hierarchical or double imprinting. The imprinting procedures described above involve the grafting templated ligand sets to preformed surfaces and thus can effect little control over the organization and structure of surface silanol groups located in and around the imprint "cavity". We reason that even better imprinting should occur if surface functionality can be manipulated and incorporated into the size and electronic mask of the imprint cavity. This would require that the template complex be associated with the developing pore surface as it is formed. We have thus a situation in which control of molecular architecture must optimally be maintained on two dimensional scales: mesoporosity with pore radii $\geq 20 \AA$ and microporosity from the point of view of creating a metal ion imprint involving tethered ligands and surface functionality on the order of 1-3 $\AA$. Procedures which can simultaneously control molecular architecture on different length scales have been referred to as "doubleimprinting" or hierarchical imprinting. 
We recently reported results of such hierarchical imprinting of metal ion sorbents (Dai et al., 2000). These doubly-imprinted, hybrid mesoporous sol-gels exhibit relative selectivity coefficients for $\mathrm{Cu}^{2+}$ over $\mathrm{Zn}^{2+}$ which are significantly greater than the previous values we reported in our $1^{\text {st }}$-generation imprint coating method. Furthermore, the procedure, by which mesoporosity is maintained in the sol-gel matrix while atomic scale imprinting of the pore surfaces is accomplished, is an exceedingly simple, "one-pot" reaction involving readily available reagents. For example, mesoporous $\mathrm{Cu}^{2+}$ imprinted sol-gel sorbents were prepared by mixing a surfactant (e.g., cetyltrimethylammonium bromide, CTAB), $\mathrm{Si}(\mathrm{OEt})_{4}$, the template complex $\left[\mathrm{Cu}(\text { appts })_{2}\right]^{2+}$ in water with a base catalyst at $100{ }^{\circ} \mathrm{C}$ for $24 \mathrm{~h}$. Exposure of the blue solids to acid removed the $\mathrm{Cu}^{2+}$ template to give white, mesoporous solids with overall surface areas in the range of $200-600 \mathrm{~m}^{2} / \mathrm{g}$. Preliminary binding and selectivity data for the sorbents are summarized in Table 4. In two cases, selectivity coefficients $k$, and relative selectivity constants $k^{\prime}\left(\mathrm{Zn}^{2+}\right.$ competitor) were obtained which were more than 5 times as large as those obtained by our $1^{\text {st }}$ - and $2^{\text {nd }}$-generation imprinting procedures described above. These new selectivity values are the largest that we are aware of in the current literature.

Table 4 Binding Affinity and Selectivities of Hierarchical Imprinted Sorbents. ${ }^{\text {a }}$

\begin{tabular}{|c|c|c|c|c|c|c|c|c|}
\hline Type & $\begin{array}{l}\text { Soluti } \\
{\left[\mathrm{Cu}^{2+}\right]}\end{array}$ & $\begin{array}{l}(\mathbf{M})^{b} \\
{\left[\mathrm{Zn}^{2+}\right]}\end{array}$ & $\begin{array}{c}\% \mathrm{Cu}^{2+} \\
\mathrm{Abs}^{\mathrm{d}}\end{array}$ & $\begin{array}{c}\% Z^{2+} \\
\operatorname{Abs}^{\mathrm{d}} \\
\end{array}$ & $\begin{array}{c}K_{\mathrm{d}}\left(\mathrm{Cu}^{2+}\right) \\
(\mathrm{mL} / \mathrm{g})\end{array}$ & $\begin{array}{c}K_{\mathrm{d}}\left(\mathrm{Zn}^{2+}\right) \\
(\mathrm{mL} / \mathrm{g})\end{array}$ & $\boldsymbol{k}$ & $\boldsymbol{k}^{\prime}$ \\
\hline Nonimp-aapts $(\mathrm{CTAB})^{\mathrm{c}}$ & 0.001 & 0.001 & 99.66 & 99.77 & 29000 & 44000 & 0.66 & - \\
\hline Imp-aapts (CTAB) ${ }^{\mathrm{c}}$ & 0.001 & 0.001 & 99.17 & 10.13 & 11000 & 67 & 160 & 240 \\
\hline Nonimp-aapts (SDS) ${ }^{\mathrm{e}}$ & 0.001 & 0.001 & 96.07 & 44.59 & 2400 & 71 & 34 & - \\
\hline Imp-aapts (SDS) & 0.001 & 0.001 & 99.56 & 13.31 & 23000 & 15 & 1500 & 44 \\
\hline Nonimp-aapts (SDS) & 0.001 & 0.01 & 93.37 & 10.64 & 1400 & 10 & 140 & - \\
\hline Imp-aapts (SDS) & 0.001 & 0.01 & 99.98 & 2.40 & 82000 & 2.5 & 33000 & 240 \\
\hline
\end{tabular}

${ }^{\text {a }}$ Competitive loading of $\mathrm{Cu}^{2+}$ and $\mathrm{Zn}^{2+}$ by $\mathrm{Cu}^{2+}$-imprinted and control blank mesoporous sorbents $(\mathrm{pH}=$ 5)

${ }^{\mathrm{b}}$ Initial conc.

${ }^{c}$ aapts imprinted and nonimprinted sorbents prepared with $\mathrm{CTAB}$; ${ }^{\mathrm{d}}$ percentage metal ion absorbed; eSDS: sodium dodecylsulfate.

Our imprinting studies have resulted in several generations of procedures which have exhibited increased control of the molecular architectures critical to the design and synthesis of ion selective sorbents. The two properties that are important to obtain fast and selective ion binding are mesoporosity and multiple binding imprints made up by a combination of surface groups (e.g., Si-OH, Si-O-Si) and tethered ligands. Furthermore, based on the hierarchical $\left(3^{\text {rd }}\right.$ generation) imprinting studies, better, more selective ion binding may be attained when the emplate-ligand complex is present during the condensation of colloidal silica particles as the 
silicate pore surfaces are formed. We speculate that under these conditions, both surface silanol groups as well as bidentate, chelating ligands [for example $\mathrm{N}^{\sim} \mathrm{N} \sim \mathrm{Si}(\mathrm{OR})_{3}$ ] are important components of the imprint cavity which lead to more effective discrimination between target and competitor ions. Although the studies we completed were mainly designed to illustrate the concepts underlying ion imprinting strategies, we see no obvious impediments to the application of these procedures to a wide variety of ligands, metal oxide support materials, and metal ions targeted by DOE-EM programs.

\section{Relevance, Impact, and Technology Transfer}

Toxic metals such as $\mathrm{Hg}^{2+},{ }^{90} \mathrm{Sr}^{2+},{ }^{137} \mathrm{Cs}^{+}$and actinides are among the principal components of hazardous wastes generated from weapon materials production. ${ }^{1}$ Their separation and removal are currently one of the most pressing environmental restoration problems facing the Department of Energy. In particular, high level radioactive waste is stored at DOE facilities at several locations across the country. ${ }^{1}$ Many such storage facilities are inadequate by the current standards. Leaching of the waste from the storage tanks into neighboring groundwater has been reported. This high-level waste is composed of a host of chemical constituents, and four radiological constituents. ${ }^{90} \mathrm{Sr}$, a fission product, has been generated in large quantities from the production of nuclear power and weapons. ${ }^{1}$ It contributes to much of the radioactivity of the high-level waste stored at DOE sites across the country. ${ }^{1}$ The high-level tank waste is a highly alkaline mixture containing many chemical constituents.

The removal of these metal ions from waste solutions is traditionally accomplished through ion exchange or metal-ligand complexation in organic polymer beads and solvent-extraction agents. ${ }^{22}$ The use of inorganic ion exchangers such as crystalline silicotitanates $(\mathrm{CSTs})^{23}$ and ion exchange resins ${ }^{2}$ relies on the substitution of cations (e.g., $\mathrm{Na}^{+}$with $\mathrm{Cs}^{+}$) with ions from the surrounding fluid medium. Ligands with high affinity for target metals have been immobilized to organic polymers to remove toxic metals. ${ }^{24}$ New ion exchange resins and inorganic materials are actively being investigated to improve affinity or selectivity for target ions in the cleanup of multicomponent waste media. ${ }^{22}$

Recently, sol-gel materials containing organofunctional groups cross-linked by $\mathrm{SiO}_{2}$ have attracted considerable attention in the areas of catalysis, ceramics, separation science, and materials chemistry. ${ }^{6,7}$ Organic functional groups L are grafted onto sol-gel precursors $(\mathrm{RO})_{3} \mathrm{Si}$ $\mathrm{X}-\mathrm{L}$, and hydrolyzed with $\mathrm{Si}(\mathrm{OR})_{4}$ to produce what has been referred to as hybrid sol-gels which incorporate these functional groups into the bulk of the porous silicate matrix. ${ }^{22}$

We investigated and developed the chemistry of imprinted organofunctional sol-gels targeted for the separation and recovery of toxic metals in this project. The results from the EMSP supported research show that (a) the ligand $\mathrm{L}$ in the organofunctional sol-gels retain their high affinity for the target metal ions; (b) the imprinting, which takes place during the formation

of these rigid solid state networks, further enhances both their capacities and selectivities; (c) the 
removal of metal ions from the aqueous solutions by these hydrophilic metal oxide-based solgels is fast; (d) alkaline-stable, ligand-grafted $\mathrm{ZrO}_{2}-\mathrm{SiO}_{2}$ sorbent is a potential sorbent for metal ion extraction in highly basic media. Metal ion binding and release in these sorbents can easily be controlled by a number of factors including $\mathrm{pH}$ and nature of the solvent. Thus, these sorbents were very cost efficient due to their quick and simple recyclability. Finally, the hydrophilic nature of the hydroxylated surfaces of metal oxide-based solids should make ion transport in these porous solids intrinsically fast. ${ }^{3}$ This property potentially solves a problem frequently encountered with ion exchange polymers based on hydrophobic organic resins. ${ }^{2}$

\section{Project Productivity}

Good productivity was achieved in this project as evidenced by the record of publications, presentations, and training of graduate and undergraduate students who are potential future work force in environmental science and engineering in the U.S. Several more papers are being drafted and we plan to submit them shortly. This EMSP project, which has been focused on toxic metal $\mathrm{Cu}^{2+}$-imprinted hybrid sol-gels, clearly established the imprinting principle and scientific basis, as well as the potentials of these imprinted organofunctional materials for toxic metal separation. Future work will be needed to realize bench scale processes for the use of these new sol-gel sorbents.

\section{Personnel Supported}

Principal Investigators and Research Associates:

Ziling (Ben) Xue, ${ }^{1}$ Craig E. Barnes, ${ }^{2}$ Shang Dai, ${ }^{3}$

Djawad Waezsada, ${ }^{1,2,3}$ Yihui Yang ${ }^{1,2}$

Graduate Students: $\quad$ Yongsoon Shin, ${ }^{2,3}$ Ph.D. awarded in 1999

Mark C. Burleigh, ${ }^{1,3}$ Ph.D. awarded in 2000

Hee-Jung Im, ${ }^{1}$ Ph.D. expected in 2001-2002 school year

Suree Saengkerdsub, ${ }^{2}$ Ph.D. expected in 2001-2002 school year

Bryan C. Fagan, ${ }^{1}$ M.S. awarded in 2000

John W. Clavier, ${ }^{2}$ M.S. awarded in 2000

Erin K. Myers, ${ }^{2}$ M.S. awarded in 2000

Terry L. Yost, Jr., ${ }^{1}$ M.S. awarded in 2000

Undergraduate Students: Samson Francis, ${ }^{2}$ B.S. expected in 2001-2002 school year

Jamie N. Jones, ${ }^{2}$ B.S. awarded in 2000

Jeffery B. Williams, ${ }^{2}$ B.S. awarded in 2001 
Institutions: $\quad{ }^{1}$ Department of Chemistry

University of Tennessee

Knoxville, TN 37996-1600

Phone: 865-974-3443; Fax: 865-974-3454; Email: xue@utk.edu

${ }^{2}$ Department of Chemistry

University of Tennessee

Knoxville, TN 37996-1600

Phone: 865-974-3446; Fax: 865-974-3454; Email: cebarnes@utk.edu

${ }^{3}$ Chemical Technology Division

Oak Ridge National Laboratory

Oak Ridge, TN 37831-6181

Phone: 865-576-7307; Fax: 865-574-6442; Email: dais@ornl.gov

\section{Peer Reviewed Publications}

1. S. Dai; M. C. Burleigh; J. M. Simonson; R. E. Mesmer; L. M. Toth; Z.-L. Xue

"Application of Chemometric Methods in UV-Vis Absorption Spectroscopic Studies of Uranyl Ion Dimerization Reaction in Aqueous Solutions," Radiochim. Acta, 1998, 81, 195-199.

2. S. Dai; M. C. Burleigh; Y. Shin; C. C. Morrow; C. E. Barnes; Z.-L. Xue "Imprint Coating: Novel Synthesis of Selective Functionalized Ordered Mesoporous Sorbents," Angew. Chem. Int. Ed. Engl. 1999, 38, 1235-1239.

3. S. Dai; Y. Shin; Y. Ju; M. C. Burleigh; J.-S. Lin; C. E. Barnes; Z.-L. Xue "A New Methodology to Functionalize Surfaces of Ordered Mesoporous Materials Based on Ion Exchange Reactions," Adv. Mater. 1999, 11, 1226-1230.

4. Y. S. Shin; M. C. Burleigh; S. Dai; C. E. Barnes; Z.-L. Xue "Investigation of Uranyl Adsorption on Mesoporous Titanium-Based Sorbents," Radiochim. Acta, 1999, 84, 3742.

5. S. Dai; M. C. Burleigh; Y. Ju; H. J. Gao; J. S. Lin; S. Pennycook; C. E. Barnes; Z.-L. Xue "Hierarchically Imprinted Sorbents for the Separation of Metal Ions," J. Am. Chem. Soc. 2000, 122, 992-993.

6. C. E. Barnes; Y. Shin; S. Saengkerdsub; S. Dai "EXAFS Study of Uranyl Nitrate Dimer at High and Low Temperature," Inorg. Chem. 2000, 39, 862-864.

7. H.-J. Im; Y.-H. Yang; L. R. Allain; C. E. Barnes; S. Dai; Z.-L. Xue "Funtionalized Sol Gels for Selective Copper(II) Separation," Environ. Sci. Technol. 2000, 34, 2209-2214.

8. M. C. Burleigh; S. Dai; E. W. Hagaman; C. E. Barnes Z.-L. Xue "Stepwise Assembly of Surface Imprint Sites on MCM-41 for Selective Metal Ion Separations," ACS Symp. 
Series 2000, 778 (Nuclear Site Remediation), 146-158.

9. T. L. Yost, Jr.; B. C. Fagan; L. R. Allain; C. E. Barnes; S. Dai; M. J. Sepaniak; Z.-L. Xue "Crown-Ether Doped Sol-Gel Materials for Stronium(II) Separation," Anal. Chem. 2000, 72, 5516-5519.

10. B. C. Fagan; C. A. Tipple; Z.-L. Xue; M. J. Sepaniak "Modification of Micro-Cantilever Sensors with Sol-Gels to Enhance Performance and Immobilize Chemically Selective Phases," Talanta, 2000, 53, 599-608.

At least three manuscripts are currently in preparation.

\section{Interactions}

The PIs and a graduate student attended two EMSP workshops with presentations describing the progress made in this project (Chicago, 1998 and Atlanta, 2000). In addition, the PIs and graduate students attended the following national and regional meetings with presentations.

- $\quad$ 216th American Chemical Society National Meeting, Boston, MA, Aug. 23-27, 1998

(a) Comparison of Uranyl Adsorption Capacity of Various Porous Sorbents

(b) Removal of $\mathrm{Cu}^{2+}$ from Aqueous Solutions via Sol-Gel Extraction. A Molecular Imprinting Approach

- $\quad$ 217th American Chemical Society National Meeting, Anaheim, CA, Mar. 21-25, 1999

(a) Imprint Coating: Novel Synthesis of Selective Functionalized Ordered Mesoporous Sorbents

(b) Removal of $\mathrm{UO}_{2}{ }^{2+}$ and $\mathrm{Sr}^{2+}$ from Aqueous Solutions via Sol-Gel Extraction. A Molecular Imprinting Approach.

- $\quad$ 218th American Chemical Society National Meeting, New Orleans, LA, Aug. 22-26, 1999

(a) Sol-Gel Sorbents for Cesium and Strontium

(b) Studies of Strontium Binding of Phosphonate-Functionalized Sol-Gels

(c) Crown-ether Doped Sol-Gel Sorbents for Sr ${ }^{2+}$ Separation

(d) Ligand-grafted Hydrophilic Sol-gel Sorbents for Toxic Metal Separation

(e) Direct Molecular-imprinting Approach to Mesoporous Sol-gel Sorbents

(f) Combined Ionic Exchange and Ligand Modification Approaches to Highly Selective Mesoporous Silica

(g) Molecular Imprinting on Sol-gel Materials

(h) Functionalized Mesoporous Silica Sorbents for the Selective Removal of Copper(II) from Aqueous Solutions 
- $\quad$ Southeast Regional Meeting of the American Chemical Society (SERMACS-99), Knoxville, TN, Oct. 17-20, 1999.

(a) Sol-gel Sorbents Doped with Crown Ether Ligands for Sr ${ }^{2+}$ Separation

(b) Functionalized Silica Beads for the Selective Removal of Metal Ions from Aqueous Solutions

(c) Hydrophilic Sol-gel Sorbents Grafted with Ligands for Toxic Metal Separations

- $\quad$ 219th American Chemical Society National Meeting, San Francisco, CA, Mar. 26-30, 2000

Selective Adsorption of Metal Ions with Functionalized Sol-gel Sorbents via Molecular Imprinting

- 220th American Chemical Society National Meeting, Washington, DC, Aug. 20-24, 2000 Dithioethercarboxylate Funtionalized Sol-Gels for Mercury (II) Separation

- $\quad 221$ st American Chemical Society National Meeting, San Diego, CA, Apr. 1-5, 2001 Phosphonic Acid Containing Sol-gel Sorbents for Sr(II) and Uranyl: Imprinting Effects.

\section{Transitions}

Discussions were conducted by Dr. Sheng Dai with Dr. Thomas Klasson, PI of the FY99 MWFA (Mixed Waste Focus Area) project, "Demonstration of Sorbents to Meet DOE Customer Needs," to support ongoing OST (Office of Science and Technology) field demonstrations of sorbents with research results and to establish connections with potential end-users and other OST programs (ESP and MWFA). A meeting was also held jointly with Dr. Klasson and field leadership of ESP (Efficient Separations and Processing), Drs. Jerry Harness and Jack Watson.

ONDEO Nalco Co., Naperville, IL, is interested in our new ligand-tethered silica sol-gels for metal separation. Samples have been sent to the company for test.

\section{Patents and Invention Disclosures}

A U.S. patent (US 6251280, "Molecular Recognition Imprint Coatings for Selective Functionalized Mesoporous Sorbents for Separation Processes and Sensors") was issued in 2001 to Dr. Sheng Dai, Mark C. Burleigh, Yongsoon Shin (University of Tennessee Research Corporation; U. T. Battelle, LLC).

\section{Future Work}

The future research in this area would include scaling up the procedures developed in this project for field tests, and applying these procedures to new supports and ligand systems which will selectively bind the toxic or radioactive contaminants targeted by the DOE: $\mathrm{UO}_{2}{ }^{2+}, \mathrm{Cs}^{+}, \mathrm{Sr}^{2+}$, 
and $\mathrm{Hg}^{2+}$. These research areas are designed to: (1) synthesize and screen ligands for targeted ions: $\mathrm{UO}_{2}{ }^{2+}, \mathrm{Sr}^{2+}, \mathrm{Cs}^{+}, \mathrm{Hg}^{2+}$; (2) apply coating and hierarchical imprinting techniques to enhance binding affinity and selectivity; (3) extend imprinting procedures to include base stable, mesoporous supports; (4) probe the composition and structure of imprinted cavities and correlate them with the kinetics and thermodynamics of ion transport, complexation and selectivity; (5) optimize conditions by which fully loaded sorbents may be efficiently regenerated for further use; (6) continue active pursuit and collaborations with contacts within DOE-EM program for testing of imprinted sorbents under application conditions.

\section{Literature Cited}

1. U.S. DOE Office of Environmental Management Linking Legacies, 1997.

2. S. Alexandratos; D. W. Crick "Polymer-Supported Reagents: Application to Separation Science," Ind. Eng. Chem. Res. 1996, 35, 635.

3. C. J. Brinker; G. W. Scherer Sol-Gel Science; Academic Press: New York, 1990.

4. U. Schubert "Hybrid Inorganic-Organic Materials by Sol-Gel Processing of Organofunctional Metal Alkoxides," Chem. Mater. 1995, 7, 2010.

5. (a) X. Feng; G. E. Fryxell; L.-Q. Wang; A. Y. Kim; J. Liu; K. M. Kemner "Functionalized Monolayers on Ordered Mesoporous Supports," Science 1997, 276, 923. (b) A. M. Klonkowski; K. Koehler; C. W. Schlaepfer "Copper(II) in Organically Modified Silicate Gels Prepared by the Sol-Gel Method," J. Mater. Chem. 1993, 3, 105. (c) D. E. Leyden; G. H. Luttrell "Preconcentration of Trace Metals Using Chelating Groups Immobilized via Silylation," Anal. Chem. 1975, 47, 1612. (d) S. T. Beatty; R. J. Fischer; E. Rosenberg; D. Pang "Comparison of Novel and Patented Silica-Polyamine Composite Materials as Aqueous Heavy Metal Ion Recovery Materials," Sep. Sci. Technol. 1999, 34, 2723.

6. G. Wulff "Molecular Imprinting in Cross-Linked Materials with the Aid of Molecular Templates. A Way towards Artificial Antibodies," Angew. Chem. Int. Ed. Engl. 1995, 34, 1812.

7. K. J. Shea "Molecular Imprinting of Synthetic Network Polymers: The de novo Synthesis of Macromolecular Binding and Catalytic Sites," Trends Polym. Sci. 1994, 2, 166.

8. S. Dai; Y. S. Shin; L. M. Toth; C. E. Barnes "Spectroscopic Probing of Adsoption of Uranyl to Uranyl-Imprinted Silica Sol-Gel Glass via Steady-State and Time-Resolved Fluorscence Measurement," J. Phys. Chem. B 1997, 101, 5521.

9. (a) L. Maya "Sorbed Uranium(VI) Species on Hydrous Titania, Zirconia, and Silica Gel," Radiochim. Acta 1982, 31, 147. (b) A. R. Gupta; B. Venkataramani "Sorption of Uranyl Ions on Hydrous Oxides. A New Surface Hydrolys Model," Bull. Chem. Soc. Jpn. 1988, 1988, 1357. (c) S. Kaneko; S. Okuda; M. Nakamura; Y. Kubo "Adsorption of Uranium Ion in Sea Water on Coprecipitated Silica-Titania Gel," Chem. Lett. 1980, 1621. (d) Y. 
Song; H. Zhang; Q. Yang; A. Zhao "Preparation, Characterization of Crystalline Zirconium Phosphates and Study on Their Acid Stability and Ion Exchange Behavior with Uranyl Ions," J. Radioanal. Nucl. Chem. 1995, 198, 375.

10. (a) E. A. Behrens; P. Sylvester; A. Clerfield "Assessment of a Sodium Nonatitanate and Pharmacosiderite-Type Ion Exchangers for Strontium and Cesium Removal from DOE Waste Simulants," Envir. Sci. Technol. 1998, 32, 101. (b) Y. Song; H. Zhang; Q. Yang; A. Zhao "Preparation, Characterization of Crystalline Zirconium Phosphates and Study on Their Acid Stability and Ion Exchange Behavior with Uranyl Ions," J. Radioanal. Nucl. Chem. 1995, 198, 375. (c) P. T. Tanev; T. J. Pinnavaia "A Neutral Templating Route to Mesoporous Molecular Sieves," Science 1995, 267, 865. (d) U. Ciesla; D. Demuth; R. Leon; P. Petroff; G. Stucky; K. Unger; F. Schuth "Surfactant Controlled Preparation of Mesostructured Transition-Metal Oxide Compounds," J. Chem. Soc. Chem. Commun. 1994, 1387. (e) A. Clearfield "Inorganic Ion Exchangers: A Technology Ripe for Development," Ind. Eng. Chem. Res. 1995, 34, 2865. (f) U. Ciesla, M. Froba, G. Stucky, F. Schuth "Highly Ordered Porous Zirconias from SurfactantControlled Syntheses: Zirconium Oxide-Sulfate and Zirconium Oxo Phosphate," Chem. Mater. 1999, 11, 227. (g) S. A. Bagshaw; E. Prouzet; T. J. Pinnaavaia "Templating of Mesoporous Molecular Sieves by Nonionic Polyethylene Oxide Surfactants," Science 1995, 269, 1242.

11. J. S. Watson Separation Methods for Waste and Environmental Applications; Marcel Dekkar: New York, 1999.

12. (a) J. S. Bradshaw; R. M. Izatt "Crown Ethers: The Search for Selective Ion Ligating Agents," Acc. Chem. Res. 1997, 30, 338. (b) J. L. Sessler; V. Kral; J. W. Geng; R. E. Thomas; B. L. Iverson "Anion Selectivity of a Sapphyrin-Modified Silica Gel HPLC Support," Anal. Chem. 1998, 70, 2516. (c) L. Mercier; T. J. Pinnavaia "Heavy Metal Ion Adsorbents Formed by the Grafting of a Thiol Functionality to Mesoporous Silica Molecular Sieves: Factors Affecting Hg(II) Uptake," Envir. Sci. Technol. 1998, 32, 2749. (d) X. Chen; X. Feng; J. Lui; G. E. Fryxell; M. Gong "Mercury Separation and Immobilization using Self-assembled Monolayers on Mesoporous Supports (SAMMS)," Sep. Sci. Technol. 1999, 34, 1121. (e) B. Zhang; A. Clearfield "Crown Ether Pillard and Functionalized Layered Zirconium Phosphonates: A New Strategy to Synthesize Novel Ion Selective Materials," J. Am. Chem. Soc. 1997, 119, 2751.

13. S. D. Alexandratos; D. W. Crick "Polymer-Supported Reagents: Application to Separation Science," Ind. Eng. Chem. Res. 1996, 35, 635.

14. EPA: Environmental Protection Agency; RCRA: Resource Conservation and Recovery Act.

15. S. E. Manahan Environmental Chemistry; 6th Ed.; Lewis Publishers: Boca Raton, 1994.

16. M. Thomasset Metabolism and Toxicity of Strontium; P. Galle; R. Masse; Eds.; Masson: 
Paris, 1982, p. 98.

17. R. A. Bartsch; H. Takashi Metal Ion Separations with Lariat Ether Ion-Exchange Resins. ACS Symp. Ser., 1999; Vol. 716, p. 183.

18. (a) L. S. Bradshaw; R. M. Izatt; A. V. Bordunov; C. Y. Zhu; J. K. Hathaway Crown Ethers; J. L. Atwood; J. E. D. Davies; D. D. Macnicol; F. Vogtle; J. M.. Lehn; G. W. Gokel; Eds.; Elsevier: New York, 1996; Vol. 1, p. 35. (b) G. W. Gokel Crown Ethers and Cryptands; Royal Society of Chemistry: Cambridge, 1991.

19. (a) C. T. Kresge; M. E. Leonowicz; W. J. Roth; J. C. Vartuli; J. C. Beck "Ordered Mesoporous Molecular Siever Synthesized by a Liquid-Crystal Template Mechanism," Nature 1992, 359, 710. (b) J. S. Beck; J. C. Vartuli; W. J. Roth; M. E. Leonowicz; C. T. Kresge; K. D. Schmitt; C. T.-W. Chu; D. H. Olson; E. W. Sheppard; S. B. McCullen; J. B. Higgens; J. L. Schlenker "A New Family of Mesoporous Molecular Sieves Prepared with Liquid Crystal Templates," J. Am. Chem. Soc. 1992, 114, 10834.

20. T. E. Mallouk; J. A. Gavin "Molecular Recognition in Lamellar Solids and Thin Films," Acc. Chem. Res. 1998, 31, 209.

21. A. R. Badiei; L. Bonneviot "Modification of Mesoporous Silica by Direct Template Ion Exchange Using Cobalt Complexes," Inorg. Chem. 1998, 37, 4142.

22. $\quad$ "Efficient Separations and Processing Crosscutting Program," Department of Energy Technology Summary, Office of Environmental Management, Technology Development, DOE/EM-0249 June 1995.

23. (a) E. A. Behrens; P. Sylvester; A. Clerfield "Assessment of a Sodium Nonatitanate and Pharmacosiderite-Type Ion Exchangers for Strontium and Cesium Removal from DOE Waste Simulants," Envir. Sci. Technol. 1998, 32, 101. (b) D. M. Poojary; R. A. Cahill; A. Clearfield "Synthesis, Crystal Structures, and Ion-Exchange Properties of a Novel Porous Titanosilicate," Chem. Mater. 1994, 6, 2364.

24. S. K. Sahni; J. Reedijk "Coordination Chemistry of Chelating Resins and Ion Exchangers," Coor. Chem. Rev. 1984, 59, 1. 